\title{
BIM Performance, Project Complexity, and User Satisfaction: A QCA Study of 39 Cases
}

\author{
Hui-jie Jiang, ${ }^{1}$ Zhi-peng Cui ${ }^{D},{ }^{2}$ Hang Yin $\mathbb{D}^{3},{ }^{3}$ and Zhong-bao Yang ${ }^{4}$ \\ ${ }^{1}$ School of Construction and Environmental Engineering, Shenzhen Polytechnic, Shenzhen, China \\ ${ }^{2}$ School of Urban Economics and Management, Beijing University of Civil Engineering and Architecture, Beijing, China \\ ${ }^{3}$ College of Management and Economics, Tianjin University, Tianjin, China \\ ${ }^{4}$ ShenZhen Dongsen Construction Project Management Co., Ltd., Shenzhen, China \\ Correspondence should be addressed to Zhi-peng Cui; cuizhipeng@bucea.edu.cn
}

Received 14 December 2020; Revised 6 August 2021; Accepted 9 September 2021; Published 25 September 2021

Academic Editor: Luís C. Neves

Copyright (C) 2021 Hui-jie Jiang et al. This is an open access article distributed under the Creative Commons Attribution License, which permits unrestricted use, distribution, and reproduction in any medium, provided the original work is properly cited.

\begin{abstract}
Although the realization of building information modeling (BIM) performance is the basis for the generation of user's satisfaction, few studies have explored the influence path between BIM performance and BIM user's satisfaction in recent years. Therefore, to enrich the research results of BIM user's satisfaction and provide reference schemes for engineering practice, this study adopts the fsQCA (fuzzy-set qualitative comparative analysis) method, taking 39 project cases using BIM technology as the base sample to analyze the influence path between BIM performance and user's satisfaction. Moreover, this study is based on the configuration theory, examining four elements of BIM performance: BIM accuracy, information integration, functional advantages and manager support, and the complexity of the project. Finally, this study identifies three types of configuration results: performance type, support type, and comprehensive type. The performance type can achieve high user satisfaction in relatively complex projects; the support type requires executive support to improve user satisfaction in less complex projects, and the comprehensive type improves satisfaction through multiple BIM performances without considering project complexity.
\end{abstract}

\section{Introduction}

Relying on potential advantages such as maximizing efficiency and minimizing error, building information modeling (BIM) has been extensively practiced in many fields of engineering projects [1]. In practical engineering projects, the most commonly used BIM functions include project cost estimation, design constructability improvement, construction schedule and quality monitoring, equipment operation tracking, and sustainability analysis $[2,3]$. At the same time, government departments are gradually releasing various documents related to the implementation of BIM, including guidance opinions, implementation routes, and operation instructions $[4,5]$. This requires further largescale projects to consider the application of BIM technology to improve project construction efficiency. BIM technology has been widely recognized in the civil engineering field because of its advantages; however, it has inevitable defects in its practical application, such as a large gap between the actual application effect and the potential advantages, which causes decision-makers to doubt the actual service effects of BIM technology [6]. According to the Smart Market research report, more than $55 \%$ of design and construction companies do not believe that BIM can achieve the most basic return on investment, and only $25 \%$ of design companies believe that BIM has created satisfactory value [7]. Therefore, the improvement of user's satisfaction with BIM has become a major issue in this field.

Extensive researches have shown that BIM performance associates with user's satisfaction. On the one hand, the integration of information in creation, sharing, utilization, and management can increase the stickiness of BIM users and the high-quality functions provided by the BIM system enhance user's experience [8]. On the other hand, the complexity of BIM function and the inherent thinking that input costs and benefits are unbalanced from traditional 
owners makes a negative relationship between BIM performance and user's satisfaction [9-11]. It is not uncommon that most previous researches attempted to navigate the tension between BIM user's satisfaction and BIM performance by considering a certain factor or a certain category of factors $[8,12,13]$. However, these studies underplay that satisfaction is the sum of positive or negative reactions held under the interaction of multiple factors [14] and do not systematically analyze the combinations of different factors, let alone the impact of external factors which cause BIM performance to fail even though doing so would provide ways to positively impact user satisfaction. In addition, project complexity as one of the most representative project characteristics that moderates the relationship between most independent variables and satisfaction is still neglected by existing studies, especially when discussing BIM performance and user's satisfaction [15]. To address this research gap, this study adopts a configurational perspective which has proposed that the core strategy focuses on how to achieve the optimal output value by matching structure, elements, and externalities [16] to investigate how BIM performance influences user's satisfaction.

Based on the above, the fuzzy-set qualitative comparative analysis (fsQCA) method is employed in this study. With a data set of 39 engineering project cases using BIM technology, this study discusses the impact of different dimensions of BIM performance on user's satisfaction, depending on the degree of project complexity. Moreover, this study identifies four impact paths toward high BIM user's satisfaction, and three configuration types that lead to high user's satisfaction. This research contributes to the relevant literature in several ways and also has practical significance for both owner and contractor in terms of improving BIM user's satisfaction.

\section{Literature Review and Research Propositions}

2.1. BIM Performance. Although users in the BIM market may have subtle understanding biases due to different usage patterns, there are signs that BIM tools and processes are approaching a tipping point in most market players [17]. For example, the Chinese market released unified standards for the application of building information models in 2017 [18]. International markets, including the United Kingdom and the United States, have also standardized the use of quantitative indicators for three-dimensional models of engineering activities. The progress of the BIM market makes the concept of BIM performance, which is used to evaluate BIM tools and application effects, gradually recognized and stable. Succar et al. [19] argued that BIM performance includes five basic elements: capability stage (to describe the different levels of the following four elements in different project stages), maturity, capability set, organizational scale, and geometric precision.

Existing research has further integrated and refined the composition of BIM performance. Liao and Teo [20] have stated that the accuracy and functional advantages of BIM are basic guarantees of its successful application in practical engineering. Among them, "accuracy of BIM" is named after the combination of maturity and geometric accuracy because they are similar in evaluation bases [21]. "Functional advantages" refers to the effects arising from the capability set of BIM technology [22]. However, some studies have indicated that the limitation of additional input and ineffective cooperation between participants are important obstacles hindering the implementation of BIM. Zheng et al. [23] have stated that the support of senior management can provide the human and material resources needed for product innovation so as to further improve the success rate of innovation. Although the initial BIM performance did not specify the element of manager support, the evaluation of organizational performance was mostly based on the support of the manager [24]. In addition, Mahamadu et al. [25] have added "information integration" to the evaluation index of BIM performance, which includes timely information transmission and integrity of content and format. Zheng et al. [23] have argued that the evaluation of each capability stage of BIM performance requires the integration of information as an important indicator.

In summary, when analyzing the impact of BIM performance on user's satisfaction, this study defines the concept as the evaluation framework of BIM use effect, including four elements: BIM accuracy, information integration, functional advantages, and manager support.

2.2. Project Complexity. The definition of complexity in different research fields is not uniform. As described by Anderson [26], there is no uniform and recognized definition of complexity in the study of complex systems because of its complexity. Despite the inherent difficulties and differences in definitions of complexity, there are elements of structure, dynamics, and interaction in the accepted definition criteria [27]. Project complexity can be measured according to the TOE theory, that is, technical latitude, organizational latitude, and environmental latitude [28]. However, recent studies have found that with the proliferation of information integration in projects, it is clear that these three dimensions cannot cope with "complex" demands. On this basis, $\mathrm{He}$ et al. [29] outlined that the structure, dynamics, and interaction standards of project complexity can be further reflected in six dimensions: information complexity, task complexity, technical complexity, organizational complexity, environmental complexity, and target complexity, and gave corresponding measurement items for each dimension. Following this, the current study takes six dimensions of project complexity as the measurement basis to measure project complexity in a more objective and detailed manner.

In configuration theory, the difference in configuration comes from different external circumstances. For engineering projects, project complexity determines most of the external environmental factors and influences project management and important decisions in project management [30]. The more complex the project, the greater the potential risk, and the higher the matching manager's ability. All these factors will affect user's satisfaction [31, 32]. Some recent studies have also suggested that BIM performance will 
produce different degrees of satisfaction in projects of different complexity [33-35]. For example, Hong et al. [33] have adopted two sets of structural equation models and found that the difference in project complexity led to a change in the relationship between BIM execution quality and execution intention. Based on this, this study sets project complexity as an important option in the portfolio path that affects BIM user's satisfaction.

2.3. BIM User's Satisfaction. There is an extensive difference between BIM user's satisfaction and project satisfaction. Usually, project satisfaction is directly related to project success with cost, time, and quality as evaluation indicators [36]. However, for BIM application, even if the executor completes all the contents stipulated in the contract, the owner may think that BIM has not achieved the expected effect or reached a satisfactory standard [10]. BIM technology emphasizes the importance of information, while BIM user's satisfaction emphasizes user's emotional and cognitive evaluation of the entire user experience [4]. Subsequent research has considered the concept of the environment. That is, this "evaluation" is the sum of the attitudes or perceptions given to different environments [15]. Clearly, the measure of satisfaction depends on the goals set by the owner, which need to be confirmed by the experience. Although the owners may perceive goals differently, researchers agree that the implementation effect and the implementation condition (environment) are the two basic goals. Subsequently, Ma et al. [13] have also adopted the above method to analyze the behavior choice after the use of BIM under different satisfaction levels. In this context, this study takes the implementation effect and implementation conditions as the basic principles for evaluating BIM user's satisfaction and confirms them in combination with the experience of the owners.

2.4. Research Propositions. Extant research in the field of BIM user's satisfaction has stressed the significance of BIM performance and project complexity $[8,19,31,32]$. Nevertheless, previous studies indicated the mixed impact of BIM performance on BIM user's satisfaction $[8,13,19]$. To this end, in order to explain and better understand BIM user's satisfaction in engineering projects, a configuration analysis of factors is more appropriate than only an investigation of individual causal factors. As demonstrated in Figure 1, this study constructs a complex causal relationship model between BIM performance, project complexity, and BIM user's satisfaction.

Configuration theory incorporates the principle of equifinality, based on which the outcome of interest can equally be explained by alternative sets of causal conditions that combine in sufficient configurations for the outcome $[37,38]$. BIM performance and project complexity are fundamental causal conditions to explain BIM user's satisfaction in engineering projects. For instance, Song et al. [8] have shown that the integration of information in creation, sharing, utilization, and management increased the stickiness of BIM users and that the high-quality functions provided by the BIM system enhanced user experience. Yet, Bryde et al. [9] find that BIM performance negatively affects user's satisfaction due to the complexity of BIM functions. Hence, configurations may include combinations of different dimensions of BIM performance, leading to the following proposition.

Proposition 1. No single best configuration of different dimensions of BIM performance leads to high BIM user's satisfaction, but there exist multiple, equally effective configurations of causal factors.

Configuration theory further proposes the occurrence of causal asymmetry, which means that, for an outcome to occur, the presence and absence of a causal condition depend on how this causal condition combines with one or more other causal conditions [38, 39]. For instance, since BIM performance have a mixed impact on BIM user's satisfaction [8,9], high user's satisfaction may be achieved with high BIM performance and low complexity. Moreover, project complexity determines most of the external environmental factors and influences project management and important decisions in project management [30]. The more complex the project, the greater the potential risk, and the higher the matching manager's ability. Therefore, project complexity moderates the relationship between most independent variables and satisfaction, especially when discussing BIM performance and user's satisfaction [15]. Thus, this study puts forth the following propositions.

Proposition 2. Single causal condition may be present or absent within configurations for high BIM user's satisfaction, depending on how they combine with the degree of project complexity.

Proposition 3. Configurations that lead to high BIM user's satisfaction will require the presence of at least one dimension of BIM performance.

\section{Research Design}

3.1. Data Collection. Between December 2017 and June 2019, the research team visited 87 engineering projects in China that applied BIM technology, including applications of BIM modeling, information integration, and other functions. By collating and analyzing project data, the projects that cannot provide sufficient qualitative materials used to evaluate performance, such as project contract, description of the implementation of BIM, BIM model, the general situation of the detailed project, feasibility study report, construction drawings, meeting materials, and written reports, were excluded. To this end, this study limited the scope of samples to 39 projects that can effectively describe BIM performance, project complexity, and user's satisfaction. For each project, at least five individuals participated in BIM management staff interviews. Through the interviews with BIM users of these projects, user's satisfaction could be clearly and accurately gauged. The background information of projects and participants are demonstrated in Table 1. 


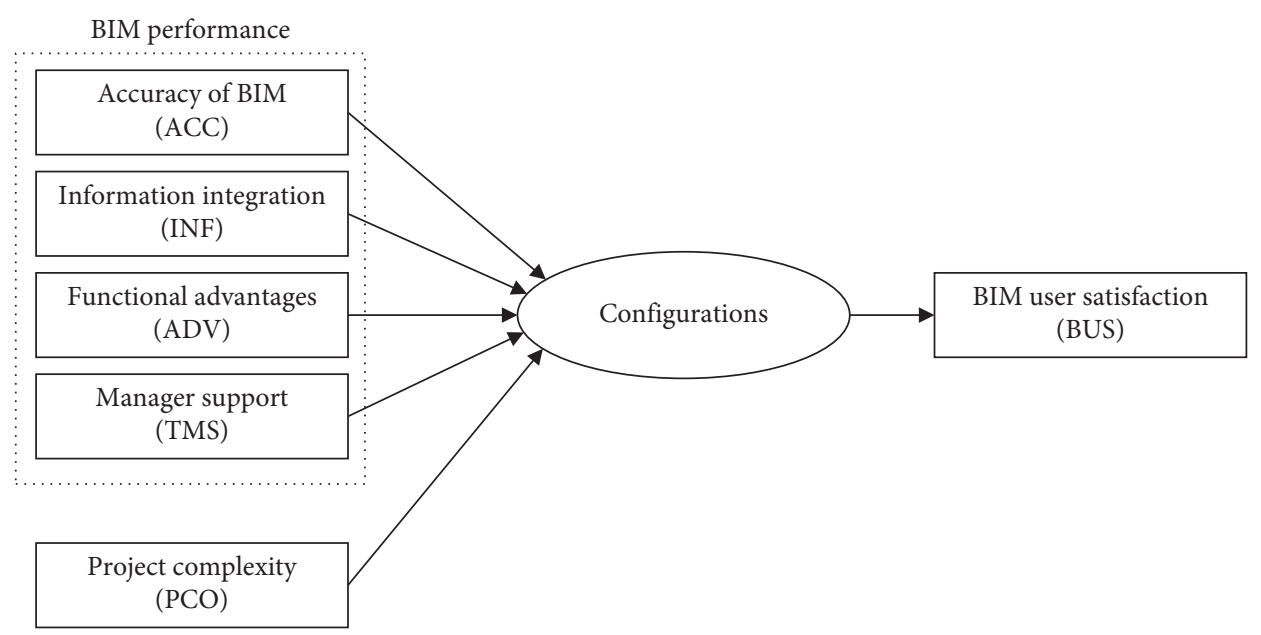

Figure 1: Research model.

TABLe 1: Project and participant background information of selected 39 projects.

\begin{tabular}{|c|c|c|c|c|}
\hline \multicolumn{3}{|c|}{ Background information } & \multirow{2}{*}{$\frac{\text { Number }}{6}$} & \multirow{2}{*}{$\begin{array}{c}\text { Proportion (\%) } \\
15.4\end{array}$} \\
\hline \multirow{13}{*}{$\begin{array}{l}\text { Project } \\
\text { Information }\end{array}$} & \multirow{6}{*}{ Project type } & Stadium & & \\
\hline & & Airport & 2 & 5.1 \\
\hline & & Subway & 3 & 7.7 \\
\hline & & Sewage treatment plant & 5 & 12.8 \\
\hline & & Dwelling house & 18 & 46.2 \\
\hline & & Hospital & 5 & 12.8 \\
\hline & \multirow{4}{*}{ Region } & North China & 6 & 15.4 \\
\hline & & East China & 19 & 48.7 \\
\hline & & Southwest China & 3 & 7.7 \\
\hline & & South Central China & 11 & 28.2 \\
\hline & \multirow{3}{*}{ Investment (yuan) } & $\leq 5$ billion & 11 & 28.2 \\
\hline & & 5-10 billion & 21 & 53.8 \\
\hline & & $>10$ billion & 7 & 17.9 \\
\hline \multirow{13}{*}{ Participant information } & \multirow{4}{*}{ Position } & Senior engineer & 106 & 52.7 \\
\hline & & Manager & 62 & 30.8 \\
\hline & & Director & 28 & 13.9 \\
\hline & & CEO & 5 & 2.5 \\
\hline & \multirow{4}{*}{ Education } & Under bachelor & 55 & 27.4 \\
\hline & & Bachelor & 121 & 60.2 \\
\hline & & Master & 23 & 11.4 \\
\hline & & Doctor & 2 & 1.0 \\
\hline & \multirow{3}{*}{ Work experience } & $1-5$ years & 65 & 32.3 \\
\hline & & $5-10$ years & 99 & 49.3 \\
\hline & & $>10$ years & 37 & 18.4 \\
\hline & \multirow{2}{*}{ Gender } & Male & 183 & 91.0 \\
\hline & & Female & 18 & 9.0 \\
\hline
\end{tabular}

3.2. Research Method: Fuzzy-Set Qualitative Comparative Analysis ( $\left.f_{s} Q C A\right)$. The research design considers the interdependencies between BIM performance and project complexity by exploring how their combined impact is linked to user's satisfaction. While a structural equation model can verify the existence of relationships and their effects on each other, it is impossible to determine the various combinations of elements. Here, the determination of configuration can be regarded as the category of qualitative research, and qualitative comparative analysis (QCA) is considered to be an effective configuration research method in many fields such as management, political economy, and media [40]. QCA has three main variations: crisp set QCA (csQCA), multivalue QCA (mvQCA), and fuzzy-set QCA (fsQCA). The first variation of QCA is csQCA which is a tool created to deal with complex sets of binary data [41]. An extension of QCA is mvQCA, which treats variables as multivalued instead of dichotomous [42]. And it has remained underutilized compared to the other two variations of QCA (csQCA and fsQCA) [42]. FsQCA addresses an important limitation of csQCA, the fact that variables are binary, thus restricting the analysis as it cannot fully capture the complexity in cases that naturally vary by level or degree $[43,44]$. This restriction of csQCA is likely an 
important reason that QCA has not been widely adopted in multiple contexts. FsQCA extends csQCA by integrating fuzzy sets and fuzzy-logic principles with QCA principles $[43,44]$, which offers a more realistic approach since variables can get all the values within the range of $0-1$. FsQCA is able to overcome several limitations of both csQCA and mvQCA and has received increased attention recently $[37,38]$, because, when applied together with complexity theory, it provides the opportunity to gain deeper and richer insight into data. As mentioned above, and considering Mendel and Korjani's [45] choice of research methods, the fsQCA is selected as the research method in this study.

The implementation process of the research method fsQCA used includes four steps [46]. (a) Building a matrix. The data of each index are obtained directly or indirectly according to the qualitative material of each sample, and the calibration is converted to a fuzzy score value of $0-1$. The transformed fuzzy score is used to construct the sample matrix, and each row of the matrix represents a configuration. (b) Merging configuration. This step identifies all the logic that might be covered in this article by merging and displaying the same configuration. (c) Minimizing the truth table. Consistency processing is used to reduce the logical possibility that the same configuration in the truth table produces an opposite structure, and the result of truth table minimization is shown. Furthermore, this result includes all configurations and theoretical expectations for the impact on BIM satisfaction. (d) Explaining and discussing the results of truth table minimization. This step compares the results with the actual situation of the case, explains the reasons for the results, and analyzes their significance for future reference.

3.3. Data Calibration and Matrix Construction. In this section, the calibration process for the condition and outcome variables and the criteria for calibration are described in detail. The condition variables include BIM performance and project complexity. BIM performance has four dimensions, including accuracy of BIM, information integration, functional advantage, and manager support. Project complexity refers to information complexity, task complexity, technical complexity, organizational complexity, environmental complexity, and target complexity. The outcome variable is BIM user's satisfaction.

3.3.1. BIM Performance. The constructs of BIM performance in this study include the accuracy of BIM (ACC), information integration (INF), functional advantage (ADV), and manager support (TMS). These constructs are also the conditional variables that determine user's satisfaction. Although the above four conditional variables all belong to one latitude of BIM performance, there are differences in how value is assigned to them. Among them, the accuracy and information integration of BIM can be assigned by analyzing the execution materials of project samples according to the evaluation indexes set in the existing studies. The evaluation method of functional advantage is to calibrate the score using cluster analysis. The value assignment method supported by the manager is the $0-1$ mode, and the specific value assignment is shown in Table 2. The process of specific assignment and calibration is as follows.

Accuracy of BIM (ACC). This study adopts the research method of Won and Lee [17]; that is, the accuracy of BIM is assigned according to the deviation between the agreed conditions of the contract and the records of the owner's demands in the meeting materials and the geometric accuracy of the actual BIM model. The results were divided into four groups: 1: complete implementation, 0.67: basic implementation, 0.33: partial implementation, and 0 : unimplemented.

Information Integration (INF). The evaluation basis of information integration is whether the information set can provide information to project participants in a timely and accurate manner. This study uses the evaluation method of this index to confirm the integration result of the BIM model on the information communication between project participants, namely, to search for the correct information integrated by the BIM model in the corresponding state by consulting the records of information exchanged between project participants. According to the information integration of the 39 samples, the information integration degrees of the samples are divided into four groups: 1 : available at any time, 0.67: mostly available, 0.33: occasionally available, and 0 : almost impossible to provide.

Functional Advantage (ADV). Uhm et al. [47] have listed several functions of current BIM technology, such as 3D visualization, design optimization, supervision tracking, and quality tracking. Bosch-Sijtsema et al. [48] have stated that the quantitative evaluation of the indicators of functional advantage mainly depends on the number of types of BIM functional advantage realization. Therefore, this study counts the number of functional advantages realized by each sample and adopted the software SPSS.22 to conduct clustering analysis, determining three intersection points: $2.25,4.88$, and 7.71 . The calibration results of functional advantage are: 0 : weak functional advantages (1-2.25), 0.33: relatively weak functional advantages $(2.26-4.88), 0.67$ : relatively strong functional advantages (4.89-7.71), and 1: strong functional advantages (7.72-9).

Managers Support (TMS). Generally, the concept of manager support is expressed in terms of technology, training, human and material resources, and other aspects and is evaluated by quantifying the number of executives supported. By analyzing the qualitative materials of 39 samples, this study finds that the number of managers who support their team members is usually grouped in two extreme situations: the support of only $30 \%$ or less of the top leaders, and the not support of only $30 \%$ or less of the top leaders. Therefore, this study uses the form of $0-1$ truth value to evaluate the above two cases.

3.3.2. Project Complexity (PCO). This study adopts 26 indicators of six latitudes proposed by He et al. [29] to evaluate the 39 samples and assign a value to their project complexity. The six latitudes refer to information complexity, task 
TABLE 2: Criteria and assignment of conditional and outcome variables.

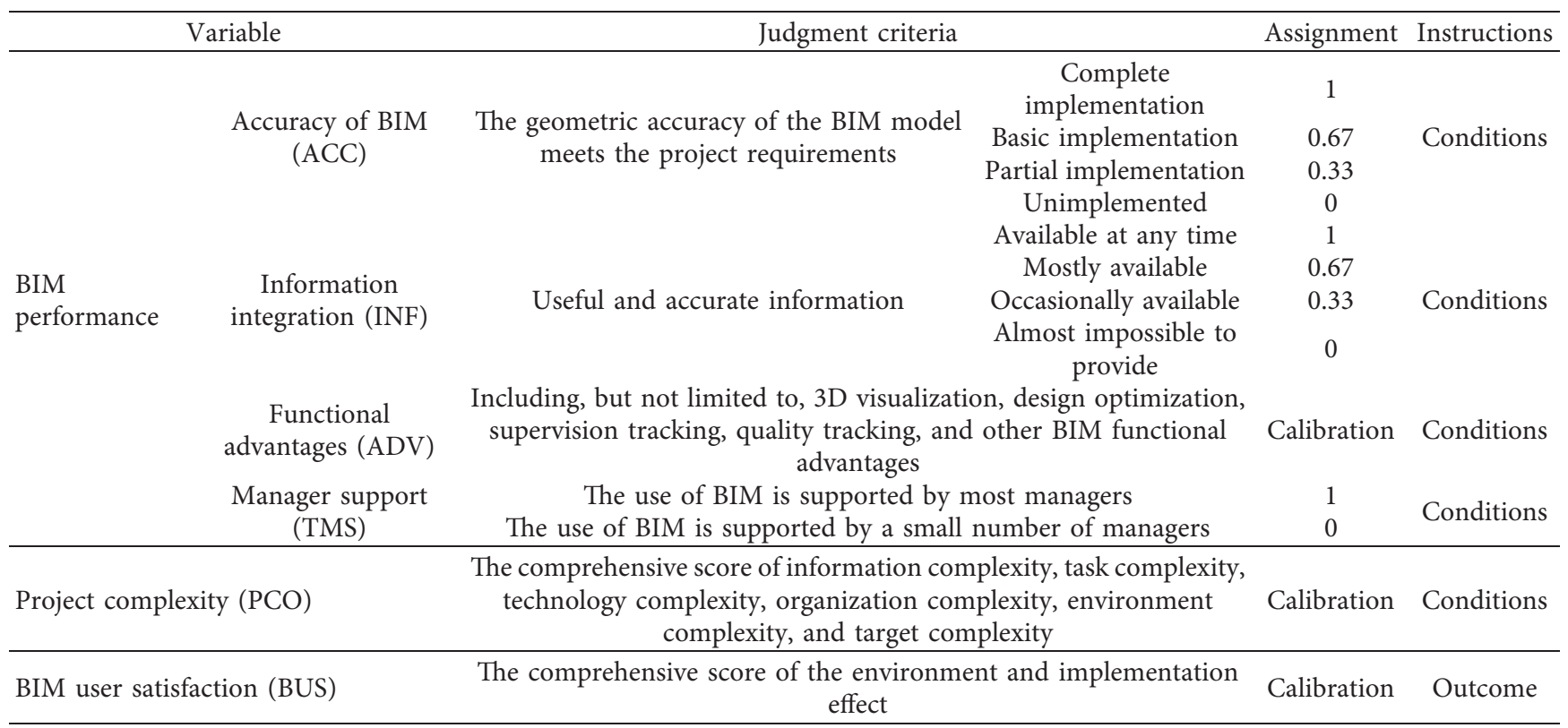

complexity, technical complexity, organizational complexity, environmental complexity, and target complexity. To ensure the accuracy of the assignment, more than 3 project stakeholders were selected to verify the final score of the project. As mentioned above, cluster analysis was used to divide the scores of all samples into three intersection points: $8.38,11.57$, and 14.80 . Thus, the calibration values of the 39 samples were divided into four groups of project complexity: 0 : low complexity $(6-8.38), 0.33$ : relatively low complexity (8.39-11.57), 0.67: relatively high complexity (11.58-14.80), and 1: high complexity (14.81-15).

3.3.3. BIM User's Satisfaction (BUS). Since users' satisfaction with BIM mostly depends on users' working experience, this study interviewed no less than 5 project managers for each project when evaluating and analyzing the index of BIM user satisfaction and assigning it a value. Scores were given for the use environment, effect expectation, and satisfaction of BIM. According to the cluster analysis, three points of score intersection of the 39 items were obtained: 12, 15.54, and 19.44. Furthermore, the BIM user satisfaction levels of the 39 projects are divided into four calibration values: 0: low satisfaction (12), 0.33: relatively low satisfaction (12.01-15.54), 0.67: relatively high satisfaction (15.55-19.44), and 1: high satisfaction (19.45-20). Criteria and assignment of all variables are shown in Table 2.

\section{Analysis and Results}

4.1. Processing of Fuzzy-Set QCA. In this study, the software fsQCA 3.0 is used for analyzing the fuzzy-set QCA including the construction and minimization of the truth table. Firstly, we sort the truth table by frequency and remove the lowfrequency configurations which threshold is 2 , based on the recommendation of Fiss [37]. Secondly, we sort the truth table by consistency and remove the configuration which threshold was set at 0.875 [49]. This number is not only much higher than the allowable minimum value of 0.75 but also can identify the obvious difference in consistency, that is, the difference between high and low satisfaction. Thirdly, we construct the truth table, which provides the basis for minimization and the minimization results (as seen in $\mathrm{Ta}$ ble 3). This table demonstrates configurations of different BIM performance and project complexity which can produce satisfactory results for users. Also, based on the abovementioned process, this study builds a separate set of truth tables (Table 4) for low satisfaction to improve the different configurations of user satisfaction and provides supplementary evidence for the above existing configurations.

4.2. Configuration Results. This study aims to identify the different impact paths of BIM performance on user's satisfaction under different project complexity conditions through fuzzy-set QCA. According to the results of the truth table, four different influence paths were identified. These were further summarized into three types of configurations: support, performance, and comprehensive.

As shown in Table 5, the consistency of configurations 1 and 2 in the performance type was 0.900 and 0.897 , respectively, while the net coverages were 0.442 and 0.426 , respectively. That is, $44.2 \%$ and $43.6 \%$ of the samples for configurations 1 and 2 can be explained by the performance in the process of generating BIM user satisfaction, respectively. This indicates that when project complexity is high, the accuracy and functional advantages of BIM (configuration 1), information integration (configuration 2), and a small amount of high-level support can produce high user satisfaction. Support type (configuration 3) shows that when project complexity is low, a large number of high-level 
TABLE 3: Truth table minimization results for positive impact of BIM usage satisfaction.

\begin{tabular}{|c|c|c|c|c|}
\hline Configuration & $\begin{array}{c}\text { Raw } \\
\text { coverage }\end{array}$ & $\begin{array}{l}\text { Unique } \\
\text { coverage }\end{array}$ & Consistency & Cases \\
\hline $\mathrm{PCO} * \sim T M S * \mathrm{ADV} * \mathrm{ACC}$ & 0.442 & 0.049 & 0.900 & C.003 C.012 C.017 C.023 C.024 C.026 C.027 C.035 C.038 \\
\hline $\mathrm{PCO} * \sim T M S * \mathrm{INF} * \mathrm{ACC}$ & 0.426 & 0.033 & 0.897 & $\begin{array}{c}\text { C. } 003 \text { C. } 008 \text { C. } 012 \text { C. } 017 \text { C. } 021 \text { C. } 023 \text { C. } 024 \\
\text { C. } 026 \text { C. } 027 \text { C. } 032 \text { C. } 035(0.67,0.67)\end{array}$ \\
\hline$\sim P C O * \mathrm{TMS} * \mathrm{INF} * \mathrm{ACC}$ & 0.195 & 0.017 & 0.923 & C.005 C.025 \\
\hline $\mathrm{TMS} * \mathrm{ADV} * \mathrm{INF} * \mathrm{ACC}$ & 0.246 & 0.099 & 0.938 & С.005 C.028 C.029 С.031 С.034 \\
\hline Solution coverage & & 0.820 & & \\
\hline Solution consistency & & 0.926 & & \\
\hline
\end{tabular}

TABle 4: Truth table minimization results for the negative impact of BIM usage satisfaction.

\begin{tabular}{|c|c|c|c|c|}
\hline Configuration & Raw coverage & Unique coverage & Consistency & Cases \\
\hline$\sim A C C * \sim A D V * \sim P C O$ & 0.550 & 0.018 & 0.884 & C.002 C.004 C.009 С.010 C.011 C.018 \\
\hline$\sim A C C * \sim I N F * \sim T M S$ & 0.518 & 0.127 & 0.829 & $\begin{array}{l}\text { C.009 C. } 010 \text { C. } 006 \text { C. } 011 \text { C. } 013 \text { C. } 016 \\
\text { C. } 020 \text { C. } 033 \text { C. } 039\end{array}$ \\
\hline $\mathrm{ACC} * \sim A D V * \mathrm{PCO}$ & 0.533 & 0.091 & 0.856 & С.022 С.008 С.014 С.015 C.019 С.032 \\
\hline Solution coverage & & 0.857 & & \\
\hline Solution consistency & & 0.773 & & \\
\hline
\end{tabular}

TABLE 5: BIM performance, project complexity, and BIM user satisfaction profile.

\begin{tabular}{|c|c|c|c|c|}
\hline & \multicolumn{2}{|c|}{ Performance type } & \multirow{2}{*}{$\begin{array}{c}\text { Support type } \\
3\end{array}$} & \multirow{2}{*}{$\begin{array}{c}\text { Comprehensive type } \\
4 \\
\end{array}$} \\
\hline & 1 & 2 & & \\
\hline ACC & - & - & $\bullet$ & $\bullet$ \\
\hline INF & & $\bullet$ & $\bullet$ & $\bullet$ \\
\hline $\mathrm{ADV}$ & 0 & & & • \\
\hline TMS & $\mathrm{O}$ & O & ○ & - \\
\hline PCO & 0 & $\bullet$ & O & \\
\hline Raw coverage & 0.442 & 0.426 & 0.195 & 0.246 \\
\hline Unique coverage & 0.049 & 0.033 & 0.017 & 0.099 \\
\hline Consistency & 0.900 & 0.897 & 0.923 & 0.938 \\
\hline Solution coverage & 0.820 & & & \\
\hline Solution consistency & 0.926 & & & \\
\hline
\end{tabular}

Note. "•" indicates that the condition variable is a high fuzzy value; "O" indicates that the condition variable has a low fuzzy value.

supports match the accuracy of BIM and the integration of information which can produce high user satisfaction. The consistency is 0.923 , and the original coverage is 0.195 . That is, the support type can explain $19.5 \%$ of the samples of satisfaction. Configuration 3 suggests that, regardless of project complexity, BIM accuracy, information integration, functional advantages, and executive support will generate high user satisfaction. The total coverage of the above configuration was 0.820 , and the total solution consistency was 0.926 , indicating that the above configuration represented $82.0 \%$ of the sample size.

This study analyzes the positive impact of BIM performance on user's satisfaction and constructs a truth table portraying the negative impact, which refers to the different configurations of lower user satisfaction. As shown in Table 4, in low complexity projects, the BIM performance lacking project accuracy and information integration would produce low satisfaction $(\sim A C C * \sim A D V * \sim P C O)$. In highly complex projects, high accuracy with few functional advantages leads to low satisfaction $(\sim A C C * \sim I N F * \sim T M S)$. When complexity is excluded, low accuracy, low information integration, and low executive support will cause low satisfaction.

\section{Discussion}

5.1. Research Findings. This study proposes that in engineering projects, BIM performance and project complexity combine to form configurations for predicting BIM user's satisfaction. In this vein, a conceptual model is constructed that servers as the basis to identify the abovementioned configurations. The results demonstrate that realization of BIM performance is always the basic factor for the improvement of satisfaction. As shown by the comprehensive type (configuration 4), without considering the complexity of the project, the four elements of BIM performance constitute the influence path of improving satisfaction. The results of the truth table do not show the configuration where accuracy does not exist, indicating that the occurrence of factors may require the adjustment or mediation of accuracy to improve satisfaction. This finding is consistent with most research on BIM user's satisfaction [8, 13].

Regarding project complexity, accuracy, integration, and functional advantages are key factors in achieving satisfaction in highly complex projects. Of importance in the 
findings is that accuracy is the foundation, whether or not another BIM performance exists. As shown in Table 4, the accuracy of BIM is the common condition for satisfying BIM users in projects with high complexity. This view is consistent with the research results of Abbas et al. [50] and the BIM accuracy and satisfaction have a direct effect. At the same time, in the three projects C.003, C.024, and C.032, the owner reported in the survey that "the drawings constructed by the $3 \mathrm{D}$ model can improve the cost accuracy to less than $3 \%$ at the beginning of the project, which not only saves a lot of estimated cost but also makes the cost work more efficiently." The findings also confirm the significance of functional advantage and information integration, which form two different configurations and do not appear at the same time. This result indicates that the above two factors have complementary effects in improving satisfaction. The interview with participants shows that, in the BIM service contract of project C.017, BIM subcontractors provide BIM services throughout the entire process from project design to operation and maintenance, among which a $3 \mathrm{D}$ visualization function, supervision tracking system, material tracking system, and maintenance and utilization tracking system have become important carriers for information transmission and sharing.

Another BIM performance condition, manager support, is of different importance, depending on the degree of project complexity. The results illustrate that the more complex the project, the lower the need for manager support in achieving satisfaction. However, manager support is an important factor that leads to BIM user satisfaction in low complexity projects. Configuration 3 shows a different combination from the performance type, which is the support type. In this configuration, user's satisfaction with BIM requires not only BIM accuracy and information integration but also the support of a large number of executives. On the one hand, this finding is consistent with the research results of Chen et al. [51], where the support provided by senior executives in technological innovation can generate internal incentives and achieve the overall promotion of BIM performance. On the other hand, in the structured interview on BIM user's satisfaction in project C.005, it was found that "although the investment of this project is not huge, all the owner's senior management hope that BIM technology can be promoted in future projects," and the senior manager supports the supervision and control of other BIM performance.

In addition to discussing the different configurations of satisfaction, this study also presents the results of the truth table showing elements that lead to user dissatisfaction. As shown in Table 3, the failure to realize the functional advantages of BIM is a necessary condition for dissatisfaction in both complex and noncomplex projects. Furthermore, although high-level support can promote satisfaction when the project complexity is low, it is not associated with user dissatisfaction in this case. Meanwhile, the combination of high accuracy and low functional advantages of BIM also produces unsatisfactory results in complex projects.
5.2. Theoretical Significance. The findings of this research contribute to the literature in several ways. First of all, this study develops research on the influence paths between BIM performance and BIM user's satisfaction. The results not only support the findings of Marefat et al. [52] and Liu et al. [35] but also supplement the above research. In addition, these results contradict research by scholars such as Qin et al. [53], who say that the accuracy and functional advantages of BIM cannot improve the satisfaction of BIM users. This is because this study considers the combination of the paths of four elements of BIM performance. On the one hand, as shown in Table 4 (configuration 1-4), the realization of functional advantages usually requires a well-matching BIM accuracy. On the other hand, as shown in Table 4 (configuration 1), even though BIM accuracy is guaranteed, the lack of more functional advantages also causes dissatisfaction among users.

Secondly, this study provides more hypothesis space for adjustment and mediation for future empirical research on BIM performance. This study adds the role of project complexity on the basis of existing research on BIM performance where different project complexity affects the transmission path of executive support to user satisfaction. In addition, all the configurations are paths showing a lack of BIM accuracy which indicates that BIM accuracy more or less regulates or mediates the impact of other BIM performance on satisfaction. Finally, the complementary effects of information integration and functional advantage are found.

Last but not least, this study promotes the development of configuration theory in the field of project management. In this study, the configuration theory of Mintzberg [54] is referenced in the field of project management, and three configurations in which BIM performance affects user satisfaction are identified. On the one hand, this discovery inherits the basic research paradigm of configuration theory. On the other hand, the adoption of this research paradigm can provide support for future research on project management.

5.3. Practical Significance. The findings of this study provide an empirical basis and reference for BIM contractors and project owners in China to improve BIM user's satisfaction in projects with different complexities. For the contractor, it is crucial to improve various contractor-related factors in the performance of BIM. At the same time, reducing the imbalance between the elements in BIM performance is the primary strategy to avoid user dissatisfaction. For the owner, BIM contractors with different capabilities can be selected according to different situations of project complexity. For example, when project complexity is high, try to choose a BIM contractor with higher useful information integration and more multifunctional advantages; when the project complexity is low, pay attention to the level of executive support for team members and the contractor. Regardless of the complexity of the project, the owner should focus on the accuracy of the model that can be provided by the BIM contractor. 


\section{Conclusion}

Based on the configuration theory and using the fsQCA method, this study analyzed 39 engineering projects that used BIM technology. The results show that three important configurations are formed after considering the relationship between BIM performance, project complexity, and BIM user satisfaction, namely performance type, support type, and comprehensive type. Among them, the performance type is used to deal with complex projects based on the accuracy, information integration, and functional advantages of BIM. The support type is used to deal with projects with low complexity, and more attention is paid to the support of senior management for the use of BIM. The comprehensive type provides a solution to improve satisfaction without considering the complexity of projects.

Although this study has certain theoretical and practical significance, it also has some limitations. First, although this study analyzes the external factors that affect BIM performance, it fails to consider the internal factors of the project itself, such as the governance model (relationship governance and contract governance). Therefore, future research can combine the characteristics of project governance to test the empirical results of performance, support, and integration. Second, although this study considers the complexity of projects, it does not analyze a certain type of special project (such as energy projects and industrial projects), thus limiting the applicability of the research results to special projects. Future research can discuss the specific performance of these three configurations in special projects.

\section{Data Availability}

The data used to support the findings of this study are available from the corresponding author upon request.

\section{Conflicts of Interest}

The authors declare no conflicts of interest.

\section{Acknowledgments}

This research was funded by the 2018 Provincial Higher Vocational Education Teaching Quality and Teaching Reform Project, Education and Teaching Reform Research and Practice Project (Project Number: GDJG2019421) and the Funded Projects of Philosophy and Social Sciences in 13th Five-Year Plan of Guangdong Province in 2017 (Project Number: GD17CGL12).

\section{References}

[1] B.-G. Hwang, X. Zhao, and K. W. Yang, "Effect of BIM on rework in construction projects in Singapore: status quo, magnitude, impact, and strategies," Journal of Construction Engineering and Management, vol. 145, no. 2, Article ID 04018125, 2019.

[2] S. Kaewunruen, J. Sresakoolchai, and Z. Zhou, "Sustainabilitybased lifecycle management for bridge infrastructure using 6D BIM," Sustainability, vol. 12, no. 6, p. 2436, 2020.
[3] K.-C. Wang, W.-C. Wang, H.-H. Wang, P.-Y. Hsu, W.-H. Wu, and C.-J. Kung, "Applying building information modeling to integrate schedule and cost for establishing construction progress curves," Automation in Construction, vol. 72, pp. 397-410, 2016.

[4] Z. A. Adamu, S. Emmitt, and R. Soetanto, "Social BIM: Cocreation with shared situational awareness," Journal of Information Technology in Construction, vol. 20, pp. 230-252, 2015.

[5] X. Xu, G. Wang, D. Cao, and Z. Zhang, "BIM adoption for facility management in urban rail transit: an innovation diffusion theory perspective," Advances in Civil Engineering, vol. 2020, 2020.

[6] W. Shen, X. Zhang, G. Qiping Shen, and T. Fernando, "The User Pre-Occupancy Evaluation Method in designer-client communication in early design stage: a case study," Automation in Construction, vol. 32, pp. 112-124, 2013.

[7] DODGE, Research Report on Application Value of BIM in China, Dodge Data \& Analytics, New Jersey, NJ, USA, 2015.

[8] J. Song, G. C. Migliaccio, G. Wang, and H. Lu, "Exploring the influence of system quality, information quality, and external service on BIM user satisfaction," Journal of Management in Engineering, vol. 33, no. 6, Article ID 04017036, 2017.

[9] D. Bryde, M. Broquetas, and J. M. Volm, "The project benefits of building information modelling (BIM)," International Journal of Project Management, vol. 31, no. 7, pp. 971-980, 2013.

[10] R. Jin, C. M. Hancock, L. Tang, and D. Wanatowski, "BIM investment, returns, and risks in China's AEC i," Journal of Construction Engineering and Management, vol. 143, no. 12, Article ID 04017089, 2017.

[11] G. Wang and J. Song, "The relation of perceived benefits and organizational supports to user satisfaction with building information model (BIM)," Computers in Human Behavior, vol. 68, pp. 493-500, 2017.

[12] J. Lee, "Environmental factors of acceptance organization affecting intention to accept bim," International Journal of Management, vol. 11, no. 4, pp. 188-200, 2020.

[13] P. Ma, S. Zhang, Y. Hua, and J. Zhang, "Behavioral perspective on BIM postadoption in construction organizations," Journal of Management in Engineering, vol. 36, no. 1, Article ID 04019036, 2020.

[14] N. Au, E. W. Ngai, and T. E. Cheng, "Extending the understanding of end user information systems satisfaction formation: an equitable needs fulfillment model approach," MIS Quarterly, vol. 32, no. 1, pp. 43-66, 2008.

[15] C. Merschbrock and B. E. Munkvold, "How is building information modeling influenced by project complexity?" International Journal of E-Collaboration, vol. 10, no. 2, pp. 20-39, 2014.

[16] D. Miller, "Configurations of strategy and structure: towards a synthesis," Strategic Management Journal, vol. 7, no. 3, pp. 233-249, 1986.

[17] J. Won and G. Lee, "How to tell if a BIM project is successful: a goal-driven approach," Automation in Construction, vol. 69, pp. 34-43, 2016.

[18] MOHURD, Standard for Classification and Coding of Building Information Model, China Construction Industry Publication, Beijing, China, 2017.

[19] B. Succar, W. Sher, and A. Williams, "Measuring BIM performance: five metrics," Architectural Engineering and Design Management, vol. 8, no. 2, pp. 120-142, 2012.

[20] L. Liao and E. A. L. Teo, "Critical success factors for enhancing the building information modelling implementation in 
building projects in Singapore," Journal of Civil Engineering and Management, vol. 23, no. 8, pp. 1029-1044, 2017.

[21] C. Khosakitchalert, N. Yabuki, and T. Fukuda, "Improving the accuracy of BIM-based quantity takeoff for compound elements," Automation in Construction, vol. 106, Article ID 102891, 2019.

[22] M. Oh, J. Lee, S. W. Hong, and Y. Jeong, "Integrated system for BIM-based collaborative design," Automation in Construction, vol. 58, pp. 196-206, 2015.

[23] L. Zheng, W. Lu, K. Chen, K. W. Chau, and Y. Niu, "Benefit sharing for BIM implementation: tackling the moral hazard dilemma in inter-firm cooperation," International Journal of Project Management, vol. 35, no. 3, pp. 393-405, 2017.

[24] R. Gelbard and A. Carmeli, "The interactive effect of team dynamics and organizational support on ICT project success," International Journal of Project Management, vol. 27, no. 5, pp. 464-470, 2009.

[25] A.-M. Mahamadu, P. Manu, L. Mahdjoubi, C. Booth, C. Aigbavboa, and F. Abanda, "The importance of BIM capability assessment: an evaluation of post-selection performance of organisations on construction projects," Engineering Construction and Architectural Management, vol. 27, no. 1, 2019.

[26] P. Anderson, "Perspective: complexity theory and organization science," Organization Science, vol. 10, no. 3, pp. 216-232, 1999.

[27] M. Al Hattab and F. Hamzeh, "Using social network theory and simulation to compare traditional versus BIM-lean practice for design error management," Automation in Construction, vol. 52, pp. 59-69, 2015.

[28] H. Yuan, Y. Yang, and X. Xue, "Promoting owners' BIM adoption behaviors to achieve sustainable project management," Sustainability, vol. 11, no. 14, p. 3905, 2019.

[29] Q.-h. He, L. Luo, Y.-b. Lu, and J.-s. Ren, "Investigating project measurement complexity from TO perspectives," Journal of Industrial Engineering and Engineering Management, vol. 1, 2013.

[30] L. Ma and H. Fu, "Exploring the influence of project complexity on the mega construction project success: a qualitative comparative analysis (QCA) method," Engineering Construction and Architectural Management, 2020.

[31] J. M. Jepson, K. Kirytopoulos, and K. London, "Exploring project managers' perception of stress when working in increasingly complex construction projects," Construction Economics and Building, vol. 17, no. 3, pp. 47-67, 2017.

[32] S. Winge, E. Albrechtsen, and J. Arnesen, "A comparative analysis of safety management and safety performance in twelve construction projects," Journal of Safety Research, vol. 71, pp. 139-152, 2019.

[33] Y. Hong, A. W. A. Hammad, and A. Akbarnezhad, "Impact of organization size and project type on BIM adoption in the Chinese construction market," Construction Management \& Economics, vol. 37, no. 11, pp. 675-691, 2019.

[34] J. Lee and S. Na, "Investigation of practitioners" perceptions for developing building information modelling (BIM)-Based value analysis model," International Journal of Civil Engineering \& Technology, vol. 9, no. 1, 2018.

[35] H. Liu, J. Song, and G. Wang, "Development of a tool for measuring building information modeling (BIM) user satisfaction-method selection, scale development and case study," Engineering Construction and Architectural Management, 2020.

[36] L. H. Nguyen, "Relationships between critical factors related to team behaviors and client satisfaction in construction project organizations," Journal of Construction Engineering and Management, vol. 145, no. 3, Article ID 04019002, 2019.

[37] P. C. Fiss, "Building better causal theories: a fuzzy set approach to typologies in organization research," Academy of Management Journal, vol. 54, no. 2, pp. 393-420, 2011.

[38] A. G. Woodside, "Embraceperformmodel: complexity theory, contrarian case analysis, and multiple realities," Journal of Business Research, vol. 67, no. 12, pp. 2495-2503, 2014.

[39] A. Leischnig and K. Kasper-Brauer, "Employee adaptive behavior in service enactments," Journal of Business Research, vol. 68, no. 2, pp. 273-280, 2015.

[40] S. Kraus, D. Ribeiro-Soriano, and M. Schüssler, "Fuzzy-set qualitative comparative analysis (fsQCA) in entrepreneurship and innovation research - the rise of a method," The International Entrepreneurship and Management Journal, vol. 14, no. 1, pp. 15-33, 2018.

[41] C. C. Ragin, The Comparative Method: Moving beyond Qualitative and Quantitative Strategies, University of California Press, Oakland, CA, USA, 1987.

[42] A. Thiem and A. Duşa, "QCA: a package for qualitative comparative analysis," RELC Journal, vol. 5, no. 1, p. 87, 2013.

[43] C. C. Ragin, Fuzzy-set Social Science, University of Chicago Press, Chicago, China, 2000.

[44] B. Rihoux and C. C. Ragin, Configurational Comparative Methods: Qualitative Comparative Analysis (QCA) and Related Techniques, Sage Publications, Thousand Oasks, CA, USA, 2009.

[45] J. M. Mendel and M. M. Korjani, "Theoretical aspects of fuzzy set qualitative comparative analysis (fsQCA)," Information Sciences, vol. 237, pp. 137-161, 2013.

[46] B. Vis, "The comparative advantages of fsQCA and regression analysis for moderately large-N analyses," Sociological Methods \& Research, vol. 41, no. 1, pp. 168-198, 2012.

[47] M. Uhm, G. Lee, and B. Jeon, "An analysis of BIM jobs and competencies based on the use of terms in the industry," Automation in Construction, vol. 81, pp. 67-98, 2017.

[48] P. M. Bosch-Sijtsema, P. Gluch, and A. A. Sezer, "Professional development of the BIM actor role," Automation in Construction, vol. 97, pp. 44-51, 2019.

[49] C. C. Ragin, "Qualitative comparative analysis using fuzzy sets (fsQCA)," Configurational comparative methods: Qualitative comparative analysis (QCA) and related techniques, vol. 51, pp. 87-121, 2009.

[50] A. Abbas, M. Choi, J. Seo, S. H. Cha, and H. Li, "Effectiveness of immersive virtual reality-based communication for construction projects," KSCE Journal of Civil Engineering, vol. 23, no. 12, pp. 4972-4983, 2019.

[51] Y. Chen, Y. Yin, G. J. Browne, and D. Li, "Adoption of building information modeling in Chinese construction industry: the technology-organization-environment framework," Engineering Construction and Architectural Management, vol. 26, no. 9, 2019.

[52] A. Marefat, H. Toosi, and R. M. Hasankhanlo, “A BIM approach for construction safety: applications, barriers and solutions," Engineering, Construction and Architectural Management, vol. 26, no. 9, 2018.

[53] X. Qin, M. Mancini, A. Travaglini, K. Lv, and M. Wang, "A comparative study on barriers between China and Italy in BIM adoption from the construction market perspective," Chinese Journal of Management, vol. 13, no. 11, pp. 1718-1721, 2016.

[54] H. Mintzberg, "Structure in 5's: a synthesis of the research on organization design," Management Science, vol. 26, no. 3, pp. 322-341, 1980. 